\title{
Clarithromycin and tetracycline binding to soil humic acid in the absence and presence of calcium
}

\section{Other Conference Item}

\section{Author(s):}

Christl, Iso; Ruiz, Mercedes; Schmidt, Jacob R.; Pedersen, Joel A.

Publication date:

2017

Permanent link:

https://doi.org/10.3929/ethz-b-000227878

Rights / license:

Creative Commons Attribution 3.0 Unported

Originally published in:

Geophysical Research Abstracts 19 


\title{
Clarithromycin and tetracycline binding to soil humic acid in the absence and presence of calcium
}

\author{
Iso Christl (1), Mercedes Ruiz (2), Jr Schmidt (3), Joel A. Pedersen (2,3,4)
}

(1) Institute of Biogeochemistry and Pollutant Dynamics, ETH Zurich, Zurich, Switzerland (iso.christl@env.ethz.ch), (2) Environmental Chemistry and Technology Program, University of Wisconsin, Madison, USA, (3) Department of Chemistry, University of Wisconsin, Madison, USA, (4) Department of Soil Science, University of Wisconsin, Madison, USA

Many organic micropollutants including antibiotics contain positively charged moieties and are present as organic cations or zwitterions at environmentally relevant $\mathrm{pH}$ conditions. In this study, we investigated the $\mathrm{pH}-$, ionic strength-, and concentration-dependent binding of the two antibiotics clarithromycin and tetracycline to dissolved humic acid in the absence and presence of $\mathrm{Ca}^{2+}$. The investigated compounds strongly differ in their chemical speciation. Clarithromycin can be present as neutral and cationic species, only. But tetracycline can form cations, zwitterions as well as anions and is able to form various calcium complexes. The $\mathrm{pH}$-dependence of binding to soil humic acid was observed to be strongly linked to the protonation behavior for both antibiotics. The presence of $\mathrm{Ca}^{2+}$ decreased clarithromycin binding to soil humic acid, but increased tetracycline binding with increasing $\mathrm{Ca}^{2+}$ concentration. The experimental observations were well described with the NICA-Donnan model considering the complete aqueous speciation of antibiotics and allowing for binding of cationic and zwitterionic species to soil humic acid. Our results indicate that clarithromycin is subject to competition with $\mathrm{Ca}^{2+}$ for binding to soil humic acid and that the electrostatic interaction of positively charged tetracycline-Ca complexes with humic acid enhances tetracycline binding in presence of $\mathrm{Ca}^{2+}$ rather than the formation of ternary complexes, except at very low tetracycline concentrations. We conclude that for the description of ionizable organic micropollutant binding to dissolved natural organic matter, the complete speciation of both sorbate and sorbent has to be considered. 